\title{
Bioavailability of Beclometasone From Two HFA-BDP Formulations With a Spacer
}

\author{
Amira SA Said, Salahdein AbuRuz, and Henry Chrystyn
}

\begin{abstract}
BACKGROUND: The drug delivery characteristics of each inhaler/spacer combination are unique. The spacer size as well as the presence of electrostatic charge greatly influence the inhaler dose emission and in vivo delivery. Using a previously developed urinary pharmacokinetic method, we have measured the relative lung and systemic bioavailability of beclometasone dipropionate (BDP) after inhalation from 2 hydrofluroalkane-beclometasone dipropionate (HFA-BDP) formulations when used with a spacer. METHODS: 12 healthy volunteers received 8 randomized doses, separated by $7 \mathrm{~d}$, of inhaled of BDP with either the Clenil pressurized metered-dose inhaler (pMDI; $250 \mu \mathrm{g})$ or the breath-actuated Qvar Easi-Breathe inhaler $(100 \mu \mathrm{g})$, used alone or with a spacer. The urinary amounts of BDP excreted and retained in the spacer were assayed using a liquid chromatographic mass spectrometer. The spacer was assessed after washing with a detergent solution that was either rinsed or not rinsed with water. In addition, the aerodynamic characterization of each inhaler/spacer combination was assessed using the Andersen Cascade Impactor operated at $28 \mathrm{~L} / \mathrm{min}$ using a 4-L inhalation volume. The amount of BDP deposited in the induction port, spacer, and various Anderson Cascade Impactor stages were determined. RESULTS: The in vivo 30-min urinary excretion and the in vitro fine particle dose results were only slightly affected by adding the spacer to the Clenil pMDI or the Qvar Easi-Breathe inhaler. However, the spacer significantly reduced drug particle impaction in the oropharynx and minimized deposition in the gastrointestinal tract. Therefore, using spacers with BDP inhalers is associated with a more favorable therapeutic ratio because it has little effect on lung dose, but it significantly reduced throat deposition. An improved lung deposition was achieved with non-rinsed spacers compared to spacers rinsed with water. CONCLUSION: The difference in the BDP particle size between formulations as well as spacer size greatly affected drug deposition in different regions of the respiratory tract. Key words: beclometasone dipropionate; urinary excretion; inhalation; spacers; relative lung bioavailability. [Respir Care 2019;64(10):1222-1230. (C) 2019 Daedalus Enterprises]
\end{abstract}

\section{Introduction}

Inhaled corticosteroids (ICS) have long been recognized as the cornerstone anti-inflammatory agent for asthma management in both adults and children as recommended by the British Guideline on the Management of Asthma. ${ }^{1}$ ICS can improve lung function, control symptoms, increase exercise capacity, and reduce disease flare-ups. Yet many factors can influence the effectiveness of ICS, such as the aerosol-generating system, particle size distribution of the inhaled aerosol, and the patient inhalation pattern.

The authors have disclosed no conflicts of interest.

Correspondence: Amira SA Said PhD, Department of Clinical Pharmacy, College of Pharmacy, Al Ain University of Science and Technology, Al Ain, United Arab Emirates. E-mail: amira.ahmed@aau.ac.ae.

DOI: $10.4187 /$ respcare.06689 
Despite the fact that most patients cannot demonstrate a correct inhalation technique, the pressurized metered-dose inhaler (pMDI) is still the most commonly prescribed inhaler device in clinical practice. ${ }^{2}$ Patients frequently fail to synchronize aerosol actuation with inhalation or inhale slowly after activation of the inhaler. Traditional pMDIs can deliver less than one third of the emitted dose to the lung, with the rest of medication being deposited in the oropharynx..$^{2}$ The development of spacers was an important addition to pMDIs because larger drug particles are retained on spacer walls by impaction, thus reducing the oropharyngeal deposition. As a result, patients may experience fewer local side effects from steroid aerosols, such as oral thrush, voice hoarseness, coughing, and throat discomfort. ${ }^{3,4}$ For beclometasone inhaled therapy, reducing oropharyngeal deposition is of critical importance because this drug has low first-pass metabolism compared to other ICSs. Thus, high oropharyngeal deposition can contribute to systemic side effects without any increase in clinical benefit. In addition, spacers increase the time required for propellant evaporation and reduce both the size and speed of the aerosol particles. Spacers reduce the need for patient coordination between actuation and inhalation of the aerosol. ${ }^{5}$ However, spacers can improve lung drug delivery only in patients with poor inhalation techniques; no additional benefits were observed in patients with good inhalation techniques. ${ }^{6}$

Different spacer/inhaler combinations will have different drug-delivery characteristics. Therefore, for optimal device selection, the delivery characteristics for each of these combinations should be fully assessed.

Currently, 2 brands of hydrofluroalkane-beclometasone dipropionate (HFA-BDP) pMDIs are available in the United Kingdom: Clenil Modulite (Chiesi Limited, Manchester, United Kingdom) and QVAR (Teva Pharmaceutical Industries, Petah Tikva, Israel). Because these aerosols are not equipotent, the Medicines and Healthcare Products Regulatory Agency advised that HFA-BDP pMDIs should be prescribed by brand name to limit confusion and avoid errors in prescribing. On the other hand, Clenil Modulite is equivalent to Becotide (GlaxoSmithKline, Brentford, United Kingdom), a chlorofluorocarbon (CFC)-BDP innovator product, thus a straightforward substitution of doses can be performed. ${ }^{7}$ The incorporation of BDP in a solution form in the QVAR inhaler allowed the efficient delivery of extra-fine particles that resulted in a 2-2.5-fold increase in efficacy compared to other BDP pMDI brands. ${ }^{8}$ Formulations rich in superfine particles such as QVAR $(1.1 \mu \mathrm{m})$ would be expected to provide higher lung deposition and less oropharyngeal impaction. Indeed, improved penetration of these small particles into both large and small airways would offer better bronchoconstriction relief and inflammatory control throughout the respiratory system. High lung-deposition values of $>50 \%$ were only possible

\section{QUICK LOOK}

\section{Current knowledge}

Pressurized metered-dose inhaler (pMDI) spacers have a size-selective function that retains the non-breathable large particles. This is important in inhaled steroid therapy to reduce oropharyngeal deposition. Several factors have been found to affect lung deposition from spacers, including formulation particle size, spacer size, and level of electrostatic charge on the spacer surface. Thus, optimal spacer length and handling method is specific to a particular pMDI and cannot be assumed to be optimal for other inhalers.

\section{What this paper contributes to our knowledge}

The addition of a small-volume spacer with larger drug particles delivered with the Clenil pMDI was not sufficient to allow complete evaporation of the aerosol propellant before reaching the lung, thus reducing lung deposition. On the other hand, using the same smallvolume spacer with the extrafine particles produced by the Qvar Easi-Breathe did not affect lung deposition but effectively reduced total systemic delivery of the inhaled corticosteroid.

through the introduction of HFA-solution technology because dose emission from spacers is mainly dependent on the drug, ${ }^{9}$ the formulation, ${ }^{2,10}$ the spacer size ${ }^{2,11}$ and its level of the electrostatic charge. ${ }^{12-14}$ In this study, we compared the relative lung bioavailability of beclometasone from the Clenil pMDI $(250 \mu \mathrm{g}, 2.9 \mu \mathrm{m})$ and the Qvar Easi-Breathe $(100 \mu \mathrm{g}, 1.1 \mu \mathrm{m})$ when used with a spacer. The spacer is a plastic tube that is $2.5 \times 3.5 \mathrm{~cm}$, with an overall length of $10 \mathrm{~cm}$ and a volume of $50 \mathrm{~mL}$ (Norton Healthcare, Harlow, United Kingdom, and GlaxoSmithKline).

The relative lung and systemic bioavailability of beclometasone after inhalation as measured with a urinary pharmacokinetic model has been previously reported. ${ }^{15}$ Based on this model, 3 indices can be used to describe the relative amounts of BDP deposited in the lung: the 30-min urinary excretion of either BDP, beclometasone, or beclometasone 17-monopropionate. The 24-h urinary BDP excreted and its metabolites allows an estimate of the total systemic bioavailability after inhalation.

\section{Methods}

\section{Washing of Spacers}

All methods were performed in accordance with relevant regulations and guidelines. To study the effect of 
electrostatic charges that build up inside the spacer, the spacer was evaluated after washing with a detergent solution (Fairy Liquid, Procter \& Gamble, London, United Kingdom) and then either subsequently rinsed or not rinsed with water. The spacer was left to dry at room temperature before each study.

\section{In Vitro}

According to the method mentioned in the British Pharmacopeia (2005), ${ }^{16}$ the Andersen Cascade Impactor (Copley, Scientific Ltd, United Kingdom) operating at 28 $\mathrm{L} / \mathrm{min}$ with a $4-\mathrm{L}$ inhalation volume was used to characterize the emitted dose from the Clenil and Qvar aerosols. Two actuations from the 250- $\mu$ g Clenil pMDI or 4 actuations from the 100- $\mu \mathrm{g}$ Qvar Easi-Breathe were introduced into the impactor for each inhaler or inhaler/spacer combination. For each inhalation method, 5 separate determinations were made. The amount of BDP deposited in the spacer, induction port, and different stages of the Andersen Cascade Impactor were measured using a previously validated liquid chromatographic mass spectrometric method. ${ }^{15}$ The mass median aerodynamic diameter (MMAD), fine particle dose (FPD), and total emitted dose (TED) were calculated for each inhaler with and without the spacer using CITDAS software (Copley Scientific, Colwick, United Kingdom). The TED is the total amount of drug collected from the mouthpiece, and it is expressed with respect to the nominal dose. The FPD is the cumulative amount of drug particles with size of $<5 \mu \mathrm{m}$. The MMAD is the particle size corresponding to $50 \%$ of the dose deposited in the Andersen Cascade Impactor.

\section{In Vivo Study}

Ethical approval for the in vivo study was granted from the ethics committee at the University of Huddersfield, Huddersfield, United Kingdom. Twelve healthy, nonsmoking adults (6 male) age $\geq 18$ years with an average $\mathrm{FEV}_{1}>90 \%$ predicted consented to participate in the study. In an open-label study design, subjects were randomly assigned to different treatment categories by utilizing a table of random numbers to reduce potential bias. It was previously reported that utilizing randomization was found to minimize bias to a greater extent than blinding in inhalation medications studies. ${ }^{17}$

On separate days, each subject inhaled 8 doses of BDP from either a $250-\mu \mathrm{g}$ Clenil Modulite pMDI or a100- $\mu \mathrm{g}$ Qvar Easi-breathe used alone or when attached to a spacer. The spacer arm was further divided to rinsed spacer or unrinsed spacer after washing with a detergent.

A randomized order of inhalation doses was administered with a 7-d washout period between each study inhalation. All participants were trained on the correct inhala- tion technique as recommended by the manufacturer. For the Clenil pMDI, the participants were instructed to breathe out as far as comfortable, and then, with the inhaler placed between the lips, participants were instructed to actuate the inhaler and breathe in at the same time for the full inhalation. Last, the inhaler was removed and participant held their breath for at least $10 \mathrm{~s}$, followed by slow exhalation. The same inhalation procedure was repeated for the EasiBreathe device, except that subjects were instructed to skip the coordination step between actuation and inhalation because the inhaled dose was automatically delivered during inspiration with the breath-actuated inhaler. This slow inhalation procedure continued over 3-5 s until total lung capacity was reached. Different checkpoints were monitored to ensure that the breath-actuation step occurred by checking sound and taste and by witnessing the movement of the device's external lever with the dose release. Subjects were instructed to hold their breath for $10 \mathrm{~s}$ after inhalation, and the next dose was inhaled $30 \mathrm{~s}$ later. ${ }^{18}$ For inhaler uses with the spacer, all participants were trained to successfully master the inhalation technique with the spacer per manufacturer's instruction. In summary, participants were instructed to exhale as much as possible, then to actuate the dose into the spacer followed by slow and deep inhalation for about 3-5 s, and finally to hold their breath for about $10 \mathrm{~s}$. Repeated doses were separated by $30 \mathrm{~s}$.

All subjects were instructed to empty their bladder before each study. Urine sample collection was carried out at $30 \mathrm{~min}$ after inhalations, and then cumulatively for $24 \mathrm{~h}$ after inhalation. All collected urine samples were frozen at $-20^{\circ} \mathrm{C}$ for subsequent analysis. The amounts of BDP excreted in the urine and its metabolites, as well as drug amounts retained in each spacer, were determined using a previously validated liquid chromatographic mass spectrometric method. ${ }^{15}$

According to pre-study calculations, the selected sample size in each study group to obtain an $80 \%$ power to detect a $40 \%$ difference in lung dose was 12 subjects. Statistical analysis of the 30-min and cumulative 24-h urinary excretion of BDP inhaled from each inhaler or inhaler/spacer combination were performed using a 2-way analysis of variance test using SPSS V17.0 (SPSS, Chicago, Illinois). In addition, a 1-way analysis of variance with Bonferroni correction was used to compare the urinary excretions of the different inhaler combinations. Equivalence between different inhalation methods was identified by normalizing the 30-min and cumulative 24-h urinary excretions for the nominal dose and then log transformed. From the mean square error of the analysis of variance, using subjects and inhalation method as the main factors, the mean ratio (90\% CI) was calculated. As cleared by the FDA, the $90 \% \mathrm{CI}$ for the mean ratios with a range of $80-120 \%$ is 


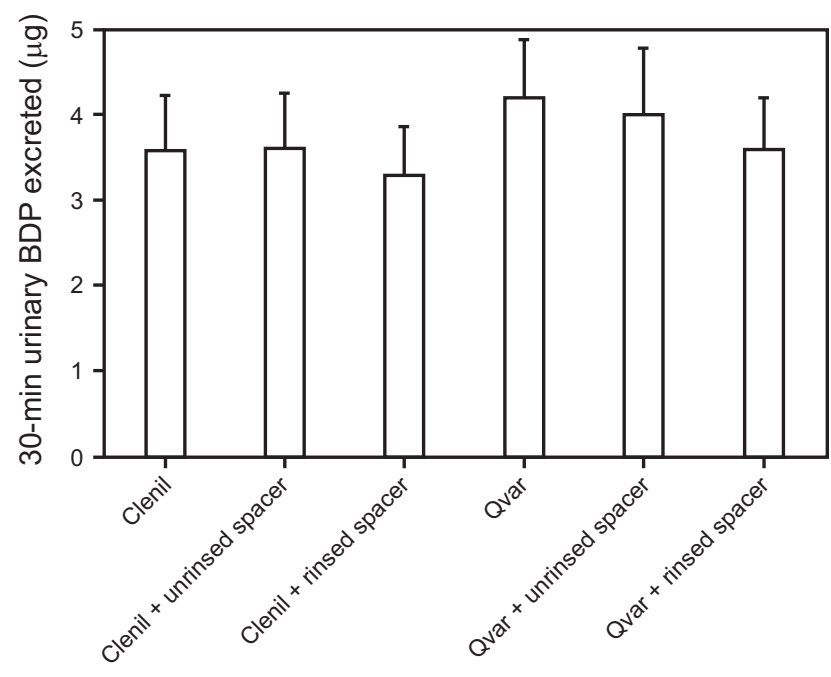

Fig. 1. Mean (SD) 30-min urinary amounts of BDP excreted after inhalation of 8 doses of BDP from Qvar Easi-Breathe $(100 \mu \mathrm{g})$ and Clenil metered-dose inhaler $(250 \mu \mathrm{g})$, with and without spacer (both rinsed and unrinsed). BDP $=$ beclometasone dipropionate.

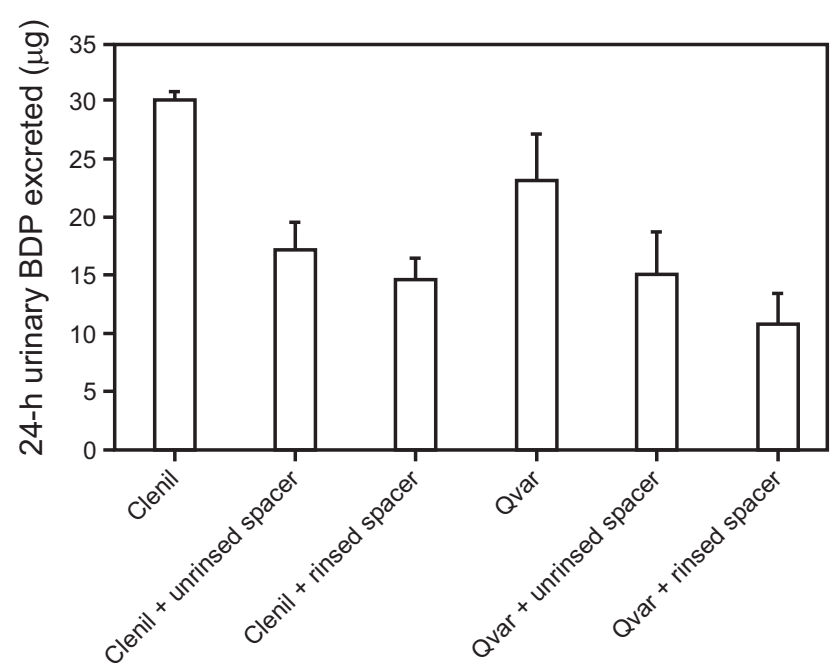

Fig. 2. Mean (SD) 24-h urinary amounts of BDP excreted after inhalation of 8 doses of BDP from Qvar Easi-Breathe $(100 \mu \mathrm{g})$ and Clenil metered-dose inhaler $(250 \mu \mathrm{g})$, with and without spacer (both rinsed and unrinsed). BDP $=$ beclometasone dipropionate.

accepted as the standard regulatory test to identify bioequivalence, even when number of subjects is small.

\section{Results}

All 12 recruited subjects (6 males) completed the study. Their mean (SD) weight, height, and age were 66.3 (8.1) $\mathrm{kg}, 166.7(7.6) \mathrm{cm}$, and $31.2(8.9) \mathrm{y}$, respectively. Figures 1 and 2 show the mean (SD) 30-min and 24-h urinary BDP excreted after inhalation of study doses, respectively. The in vitro and in vivo data are summarized in Table 1.
As presented in Table 1, using the spacer significantly reduced $(P<.001)$ systemic delivery with both inhalers. The 24-h urinary BDP significantly decreased $(P<.001)$ from 30.2 (6.6) with the Clenil pMDI alone to 17.4 (2.3) and 14.7 (1.8) with Clenil + unrinsed spacer and Clenil + rinsed spacer, respectively. With the Qvar EasiBreathe, the 24-h urinary BDP amount was significantly reduced $(P<.001)$ from 23.4 (3.9) to $15.3(3.5)$ and 11.0 (2.5) with Qvar + unrinsed spacer and Qvar + rinsed spacer, respectively. All values are expressed in $\mu \mathrm{g}$.

Similarly, in vitro data showed significant reductions $(P<.001)$ in TED from 381.8 (6.3) for the Clenil pMDI alone to 163.4 (15.2) and 112.5 (8) for Clenil + unrinsed spacer, Clenil + rinsed spacer, respectively, and from 372.6 (27.1) for the Qvar Easi-Breathe alone to 207.5 (9.6) and 138.8 (16.5) for Qvar + unrinsed spacer and Qvar + rinsed spacer, respectively. All values are expressed in $\mu \mathrm{g}$.

The data showed that more in vitro TED and in vivo 24-h urinary drug amounts were excreted with the unrinsed spacers compared to the spacers rinsed with water after detergent use. This is in correspondence with the more significant in vitro and in vivo retained drug amounts in the rinsed spacer compared to the unrinsed one. On the other hand, the 30-min urinary drug amounts $(P<.05)$ and the in vitro FPD were reduced when using the spacer with Clenil. However, greater decreases in lung deposition was encountered with the rinsed spacers compared to unrinsed ones.

The mean (SD) in vitro FPD values were 97.6 (20.8), 93.3 (17.6), 62.7 (8.2), and the mean (SD) 30-min urinary BDP values were $3.7(0.6), 3.6(0.6), 3.3(0.6)$ for the Clenil pMDI, Clenil + unrinsed spacer, and Clenil + rinsed spacer, respectively. All values are expressed in $\mu \mathrm{g}$.

The values of 30-min urinary BDP excreted and FPD after inhalation of Qvar Easi-Breathe study doses were similar to those with Qvar + unrinsed spacer, and significantly higher than those with Qvar + rinsed spacer. The mean (SD) value of FPD after inhalation of 218.0 (29.1) for the Qvar Easi-Breathe study doses was similar to that for Qvar + unrinsed spacer at 179.6 (15.1) but significantly higher than that for Qvar + rinsed spacer at 121.9 (20.9). In the same manner, the mean (SD) 30-min urinary BDP value of 3.5 (0.5) for the Qvar Easi-Breathe was similar to that for Qvar + unrinsed spacer at $3.4(0.8)$ but significantly higher than that for Qvar + rinsed spacer at 3.0 (0.6). All values are expressed in $\mu \mathrm{g}$.

The statistical comparison of the results is shown in Table 2, which represents the mean difference $(95 \% \mathrm{CI})$ for the percent of nominal dose of BDP excreted at $30 \mathrm{~min}$ and $24 \mathrm{~h}$ after study doses with and without a spacer. Table 3 presents a summary of the mean ratio $(90 \% \mathrm{CI})$ of BDP amounts between the 2 inhalers with and without the spacer with respect to the nominal dose. The overall mean 
Beclometasone Relative Bioavailability With a Spacer

Table 1. In Vivo and In Vitro Data After Inhalation of 8 Doses of BDP With and Without Spacer

\begin{tabular}{|c|c|c|c|c|c|c|}
\hline Inhaler & \multicolumn{3}{|c|}{ Clenil pMDI $(100 \mu \mathrm{g})$} & \multicolumn{3}{|c|}{ Qvar EB $(250 \mu \mathrm{g})$} \\
\hline \multicolumn{7}{|l|}{ In vitro study } \\
\hline Spacer & None & Unrinsed & Rinsed & None & Unrinsed & Rinsed \\
\hline Induction port & $251.3(22.0)$ & $28.7(7.1)$ & $24.3(6.7)$ & $121.8(15.5)$ & $7.5(3.6)$ & $3.6(1.0)$ \\
\hline Spacer deposition & NA & $240.9(26.6)$ & $305.5(33.9)$ & NA & $126.4(8.1)$ & $191.2(22.9)$ \\
\hline TED & $381.8(6.3)$ & $163.4(15.2)$ & $112.5(8.0)$ & $372.6(27.1)$ & $207.5(9.6)$ & $138.8(16.5)$ \\
\hline FPD & $97.6(20.8)$ & $93.3(17.6)$ & $62.7(8.2)$ & $218.0(29.1)$ & $179.6(15.1)$ & $121.9(20.9)$ \\
\hline MMAD & $2.8(0.4)$ & $3.1(0.2)$ & $3.3(0.3)$ & $1.2(0.2)$ & $1.0(0.2)$ & $1.1(0.2)$ \\
\hline \multicolumn{7}{|l|}{ In vivo study } \\
\hline Spacer & None & Unrinsed & Rinsed & None & Unrinsed & Rinsed \\
\hline 30-min urinary BDP & $3.7(0.6)$ & $3.6(0.6)$ & $3.3(0.6)$ & $3.5(0.5)$ & $3.4(0.8)$ & $3.0(0.6)$ \\
\hline 24-h urinary BDP & $30.2(6.6)$ & $17.4(2.3)$ & $14.7(1.8)$ & $23.4(3.9)$ & $15.3(3.5)$ & $11.0(2.5)$ \\
\hline \multicolumn{7}{|c|}{$\begin{array}{l}\text { Data are presented as mean }(\mathrm{SD}) \text {. Values are quoted in } \mu \mathrm{g} \text { except } \operatorname{MMAD}(\mu \mathrm{m}) \text {. In the in vitro study, } 5 \text { trials were performed on the on Andersen Cascade Impactor. In the in vivo study, } 12 \text { healthy } \\
\text { subjects participated. } \\
\text { BDP }=\text { beclometasone dipropionate } \\
\text { pMDI = pressurized metered-dose inhaler } \\
\text { Qvar EB }=\text { Qvar Easi-Breathe } \\
\text { MMAD = mass median aerodynamic diameter } \\
\text { TED = total dmitted dose } \\
\text { FPD = fine particle dose }\end{array}$} \\
\hline
\end{tabular}

Table 2. Mean Difference for the Percent of Nominal Dose of BDP Excreted After Study Doses With and Without Spacer

\begin{tabular}{|c|c|c|}
\hline Comparator & $\begin{array}{c}\text { BDP } 30 \text { min } \\
\text { After Study Doses }\end{array}$ & $\begin{array}{c}\text { BDP } 24 \mathrm{~h} \\
\text { After Study Doses }\end{array}$ \\
\hline Qvar EB vs Clenil pMDI & $0.3(0.2$ to 0.3$) \ddagger$ & $1.4(1.2$ to 1.7$)$ 末 \\
\hline $\begin{array}{l}\text { Clenil-unrinsed vs Qvar } \\
\text { EB-unrinsed }\end{array}$ & $-0.2(-0.3$ to -0.2$) \ddagger$ & $-1.0(-1.3$ to -0.8$)$ \\
\hline $\begin{array}{l}\text { Clenil-rinsed vs Qvar } \\
\text { EB-rinsed }\end{array}$ & $-0.2(9-0.3$ to -0.2$) \ddagger$ & $-0.6(-0.9$ to -0.4$)$ \\
\hline $\begin{array}{l}\text { Qvar EB vs Qvar } \\
\text { EB-unrinsed }\end{array}$ & $0.1(-0.2$ to 0.5$) \S$ & $8.1(6.0$ to 10.3$) \ddagger$ \\
\hline $\begin{array}{l}\text { Qvar EB vs Qvar } \\
\text { EB-rinsed }\end{array}$ & $0.5(0.2$ to 0.8$) \ddagger$ & 12.4 (10.3 to 14.6$) \neq$ \\
\hline Clenil vs Clenil unrinsed & $0.1(-0.2$ to 0.3$) \S$ & $12.8(10.6$ to 15.1$) \ddagger$ \\
\hline Clenil vs Clenil rinsed & $0.4(0.1 \text { to } 0.7)^{*}$ & 15.5 (13.3 to 17.7$) \ddagger$ \\
\hline \multicolumn{3}{|c|}{ 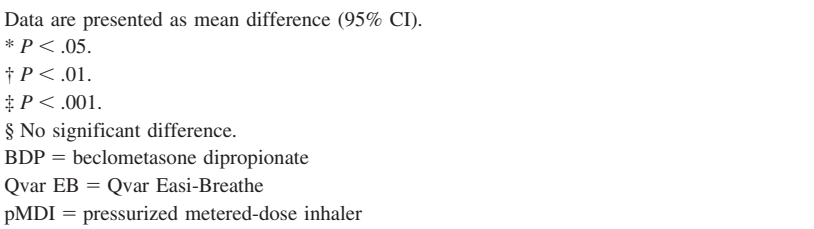 } \\
\hline
\end{tabular}

ratios of the 30-min and 24-h urinary BDP excretion for Qvar Easi-Breathe versus the Clenil pMDI were 242.5\% (90\% CI 212.5-276.8) and 196\% (90\% CI 171.8-23.7), respectively.

\section{Discussion}

The results of this study have demonstrated appreciable differences in urinary drug excretion and aerodynamic par-
Table 3. Mean Ratio of BDP Excreted With or Without Spacer (Normalized for the Nominal Dose)

\begin{tabular}{lcc}
\hline \hline & \multicolumn{2}{c}{ Cumulative Urinary Excretion } \\
\cline { 2 - 3 } & $\begin{array}{c}\text { BDP 30 min } \\
\text { After Study Doses }\end{array}$ & $\begin{array}{c}\text { BDP 24 h } \\
\text { After Study Doses }\end{array}$ \\
\hline Qvar EB vs Clenil & $242.5(212.5-276.8)$ & $196.0(171.8-223.7)$ \\
Qvar EB spacer vs & $231.9(205.0-262.5$ & $216.4(189.5-246.9)$ \\
$\quad$ Clenil spacer & $105.9(96.2-116.6)$ & $155.0(136.3-176.1)$ \\
Qvar EB vs Qvar EB & & \\
$\quad$ spacer & & \\
Clenil vs Clenil spacer & $101.2(95.3-107.6)$ & $171.1(154.8-188.9)$ \\
& \\
\hline $\begin{array}{l}\text { Data are presented as mean difference (90\% CI). } \\
\text { BDP = beclometasone dipropionate } \\
\text { Qvar EB = Qvar Easi-Breathe }\end{array}$ \\
\hline
\end{tabular}

ticle size distribution of different HFA formulations of the same drug when used with the same spacer. The difference in the particle size of these formulations (Qvar Easi-Breathe, $1.1 \mu \mathrm{m}$ vs Clenil pMDI, $2.9 \mu \mathrm{m}$ ) and the size of the spacer used greatly affected drug deposition in different regions of the respiratory tract.

In this study, both in vitro and in vivo results of inhaled BDP using the small volume spacer in both the Clenil pMDI and the Qvar Easi-Breathe significantly reduced the total systemic drug delivery. Moreover, addition of the spacer significantly reduced lung deposition with the Clenil pMDI, while it did not affect lung deposition with the Qvar Easi-Breathe.

Indeed, one of the most critical factors that affect the efficiency of asthma inhalation therapy is the inhaler device's ability to target the drug to the lung with minimal 
deposition to unwanted sites. Therefore, using spacer devices with asthma aerosols, especially ICS, is highly recommended to reduce oropharyngeal deposition, overcome the coordination problem between actuation and breathing, and improve overall lung drug delivery. ${ }^{6}$

Using the small volume spacer significantly reduced oropharyngeal deposition by both the Clenil pMDI and the Qvar Easi-Breathe, suggesting that the spacer substantially reduced the amount of drug deposited in the oropharynx by eliminating large particles deposition. Most of the large, non-breathable steroid particles deposited on the spacer walls, leaving only small, fine particles to reach the lung. This was clearly indicated by the lower 24-h urinary excretions of BDP $(P<.001)$ and the lower amount of drug deposited in the induction port of the impactor $(P<.001)$, which is considerably important as it represents the oropharyngeal cavity of the patient. This decrease in systemic delivery of drug is due to deposition of part of the dose on the walls of the spacer itself instead of deposition in the mouth. ${ }^{21}$ Spacers can trap large particles and allow smaller particles to pass through to the patient, thus depositing only a small fraction of the inhaled dose in the oropharynx.

In this study, analysis of in vitro and in vivo data clearly indicated that BDP inhaled from either the Clenil pMDI or the Qvar Easi-Breathe in combination with a spacer significantly decreased oropharyngeal deposition. This finding is supported by 2 important markers: lower 24-h urinary $\operatorname{BDP}(P<.001)$ and less accumulated drug in the impactor induction port $(P<.001)$, which represents the oropharyngeal cavity. The spacer was able to improve the drug delivery of fine particles to the lung and reduce the travel of large particles to the oropharynx. This in turn resulted in lower systemic and local side effects of inhaled BDP. ${ }^{22}$

Indeed, the higher in vitro TED for the Clenil pMDI and the Qvar Easi-Breathe compared with that when the unrinsed spacer was attached translated into higher in vivo systemic drug delivery to the main circulation. This finding agrees with many previous in vitro 8,22 and in vivo ${ }^{23-25}$ studies reporting that the use of spacers with pMDIs produce higher drug delivery to systemic circulation.

The fact that the spacer decreased systemic delivery with either inhaler is of critical importance for ICS because it reduces the occurrence of local side effects in the upper respiratory tract, such as oral thrush and candidiasis, and it reduces the systemic side effects of ICS due to minimum oral absorption. ${ }^{26}$

However, both in vitro and in vivo studies results revealed that using a spacer with the Clenil pMDI significantly reduced its lung deposition, but this did not affect lung deposition by the Qvar Easi-Breathe inhaler. This may be attributed to the differences in the emitted aerosol particle size from these 2 formulations. The Qvar EasiBreathe inhaler has been designed to produce an aerosol with a smaller particle size (1.1 $\mu \mathrm{m}$ MMAD). On the other hand, the Clenil inhaler was originally designed to produce an aerosol particle size of $2.9 \mu \mathrm{m}$ MMAD. This was achieved by adding a nonvolatile aerodynamic modulator to the HFA-BDP solution to increase the particle size. ${ }^{6}$ The addition of the spacer to the drug with the larger particle size as produced by the Clenil inhaler would be more beneficial in enhancing proper evaporation thus may confer further particle-size reduction before inhalation.

However, small volume spacers have increased the likelihood of spacer wall impaction due to greater plume velocity. This is may be more critical regarding the Clenil pMDI with its larger particle size, where the smaller size of the spacer may not be sufficient to allow complete evaporation of the aerosol propellant before reaching the lung. Furthermore, with the smaller spacer, any delay in breath-actuation coordination can lead to more loss to drugspacer wall impaction. Thus the use of this spacer may actually make the breath-actuation coordination more critical to patient lung delivery.

In contrast, the Qvar Easi-Breathe is a breath-actuated device that has been devised with a flow-triggered system driven by a spring that automatically releases the dose with the patient's inhalation. ${ }^{27,28}$ It was designed to overcome the problem of coordination between actuation and breathing. Actuation of the aerosol occurs at low inhalation flows of approximately $20 \mathrm{~L} / \mathrm{min}$. This low inspiratory flow is attainable by most patients, even those with obstructive air-flow diseases. Furthermore, the drug delivered by the Qvar Easi-Breathe is relatively stable regardless of increasing inspiratory effort. ${ }^{29,30}$

It was previously reported that good hand-breath coordination was only achievable with large volume spacers and not small volume spacers. ${ }^{31,32}$ Thus, using a small spacer with the Qvar Easi-breathe, where such coordination is no longer a requirement, would be more convenient and appropriate. This device can easily maintain the extrafine properties of these formulations, with little effect on lung deposition while avoiding the inconvenience of large volume spacers.

The above results mean that patients with asthma could achieve similar BDP lung deposition with the Qvar EasiBreathe alone or via the unrinsed spacer, but with a spacer attachment they will receive the benefit of reduced total systemic ICS delivery. This is in accordance with several previous studies reporting that using high-dose ICS in conjunction with a spacer will reduce the systemic side effects of the medication without affecting the beneficial effect of controlling asthma symptoms. ${ }^{33-35}$

Similarly, other studies reported that using HFA formulations with small tube spacers $(50 \mathrm{~mL})$ markedly reduced oropharyngeal deposition without affecting lung deposition $^{35}$ or with increased lung deposition. ${ }^{36,37}$ 
Our findings suggest that, with an extra-fine aerosol formulation such as Qvar, there is no need to use a large volume spacer because using a small volume spacer maintains the extra-fine properties of the aerosol without the need to use an inconvenient large volume spacer. This implies that the optimal spacer length effect is limited to a particular pMDI and cannot be predicted with others inhalers. Therefore, each pMDI formulation/spacer, even if it contains the same drug, needs to be fully evaluated to guide the optimal device selection.

The results of this study coincide with the British Thoracic Society recommendations for asthma management, which state that using spacers for delivering high doses of inhaled beclometasone is desirable because it significantly reduces the unwanted systemic effect of ICS without compromising its efficacy. ${ }^{1}$

Currently, clinical guidelines for the management of asthma encourage the use of spacers with asthma aerosols, especially ICS. ${ }^{1}$ The incorporation of spacers in the management of asthma can improve patients' outcomes, because spacers are easy to use, they reduce ICS systemic and local side effects, and they require less treatment time and cost. However, an inherent problem with plastic spacers is their dose inconsistencies, which might arise from the tendency of the plastic material to variably accumulate electrostatic charge on surfaces during handling. In addition, the new HFA-containing formulations are more prone to develop electrostatic charges compared to aerosols containing CFCs. ${ }^{38-40}$ The mutual repulsion between such highly charged aerosol particles with the inherent plastic spacer electrostatic charge causes significant drug deposition on the spacers' walls. Consequently, inhaled drugs will be remarkably retained within these devices, causing a significant reduction of the respirable drug dose. However, the problem of accumulation of electrostatic charges on spacer walls can be minimized by a few methods, such as washing the spacer with detergent solution without a final water rinse, ${ }^{13}$ using metal spacers, ${ }^{41}$ and actuating a few puffs into the spacer before use. .2, $^{43}$

Although metal spacers do not require washing with detergent and may resolve the problem of accumulation of electrostatic charges, plastic spacers are still the devices of choice because they cost less. In addition, it has been argued that the non-transparency of such metal spacers and the inability to see the aerosol plume created might affect patient adherence to treatment. ${ }^{44}$ In addition, priming of plastic spacers with multiple actuations may minimize the accumulation of electrostatic charges, but only in formulations that contain surfactant. ${ }^{12,13,45}$ Therefore, detergent-coated spacers represent a simple, practical, and inexpensive method for effective electrostatic charge reduction.

Although some manufacturers and regulatory agencies have advocated subsequent rinsing of detergent-coated spacers with water to avoid contact dermatitis from the detergent, this rinsing unfortunately washes the detergent from the spacer walls and results in less protection against the development of electrostatic charges. As shown in our results, washing the spacer with detergent without a final rinse yielded higher values for TED, FPD, and $30 \mathrm{~min}$ urinary drug excretion as well as less spacer deposition than the rinsed spacer. Thus our results support the superiority of the antistatic properties of the detergent-coated spacer protocol in improving drug deposition into the lung in comparison to water-rinsed ones. This is due to the greater effectiveness of this method to significantly remove surface electrostatic charges and hence improve drug output from the spacer.

Previous studies conducted with salbutamol showed a small increase in the output of the drug from both small and large volume spacers after washing the spacer with soapy water without subsequent rinsing with water. ${ }^{12,46,47}$ Previous reports indicated that the type ${ }^{12}$ and the concentration $^{13}$ of detergent used to wash spacers have little influence on the protocol's effectiveness in reducing electrostatic charges on spacer walls. The exact mechanism of action is not clear yet, but it is assumed that the hydrophilic part of the surface active agent facilitates the conduction of surface charges away from spacer walls.

In patients with poor inhalation technique who use small volume spacers, such as what we used in this study, there is an increased risk of frictional contact during inhalation. In this scenario, minimizing electrostatic charge on the spacer walls is of great importance. Studies of the delivery of salbutamol into the lung through aerosols clearly indicated that salbutamol delivery was negatively affected by delayed inhalation and positively affected by washing the spacer with detergent. ${ }^{13,44}$ This further illustrates the electrostatic charge potential as a crucial player in determining aerosol drug delivery from a pMDI/spacer combination. However, it is still unknown whether these handling differences have any clinical importance.

As shown in Table 3, the overall mean ratio of the 30-min and 24-h urinary BDP excretion values for the Qvar Easi-Breathe versus the Clenil pMDI were 242.5\% (90\% CI 212.5-276.8) and 196\% (90\% CI 171.8-223.7), respectively. This is consistent with our previous urinary pharmacokinetic study of BDP, 15 where we reported that the overall mean ratios (90\% CI) between the Qvar EasiBreathe and the Clenil pMDI, with respect to the nominal dose for the 30-min and 24-h urinary excretion were $231.4 \%$ (90\% CI 209.6-255.7) and 204.6 (90\% CI 189.6-220.6), respectively. This important finding is in agreement with previous studies that also reported an approximate 2-2.5fold greater potency of Qvar HFA-BDP compared to the same dose of other CFC-BDP MDIs. ${ }^{14,18-20}$ Observations from this study further indicate good in vitro/in vivo correlations in agreement with previous suggestions. ${ }^{48-52}$ These 


\section{Beclometasone Relative Bioavailability With a Spacer}

results indicate that the in vitro FPD and the TED parameters are the most decisive in predicting the in vivo urinary drug excretion at $30 \mathrm{~min}$ and the $24 \mathrm{~h}$, respectively.

Although our method cannot differentiate between drug distributions into different parts of the lungs, the total deposition is more closely correlated to clinical outcomes than regional deposition. ${ }^{53}$ Indeed, the future of better respiratory disease control will be more focused on improving drug delivery methods to the lung rather than targeting the introduction of new inhaled therapies. Despite the similar appearance of pMDI designs, many variations in particle size, spacer size, and washing methods have the potential to influence drug delivery. It is clear that optimizing inhalation therapy use not only would improve patient's therapeutic outcomes but also would lead to more costeffective health care. As previously published and further supported by this study, the finer details of adequate handling of spacers can maximize drug delivery, improve asthma therapeutic responses, and reduce treatment costs.

Therefore, determining the exact handling of various inhalers and spacers should significantly improve asthma management. It is inappropriate to combine any formulation with any spacer device just because it fits the mouthpiece adapter without first considering the aerosol characteristics. Each asthma pMDI formulation/spacer combination is unique and needs to be fully evaluated, even if it contains the same drug, to guide optimal device selection. Further, considering the low therapeutic index and the high cost of ICS, it is safer and more cost-effective to optimize drug delivery to the respiratory tract.

\section{Limitations}

This study provides valuable insights on different factors that affect pulmonary drug deposition when using inhaler devices, such as drug formulation, particle size, spacer size, and the method of handling spacers. In this small study, however, we only included 12 healthy subjects; further studies are needed. Research with healthy volunteers is designed to develop new knowledge; to assure direct benefit to patients, this study should be repeated in subjects with asthma.

\section{Conclusion}

The in vivo and in vitro results of this study indicate that substantial differences in inhalation devices, such as drug particle size, impact of spacer use, and electrostatic charge presence, greatly influence drug deposition in various regions of the respiratory tract even when using different formulations of the same drug with the same spacer.

Indeed, even with formulations rich in extra-fine particles such as that with the Qvar Easi-Breathe, the use of the more convenient small volume spacer was still beneficial in decreasing total systemic ICS delivery without affecting lung deposition. The Clenil pMDI, however, with its larger particle size, had lower total lung deposition with the small volume of the spacer. There is no general rule for which spacer best fits a given inhaler, and each pMDI/spacer combination needs to be fully evaluated for ideal device selection, even if it contains the same drug.

\section{REFERENCES}

1. BTS/SIGN. (2018) British Guideline on the Management of Asthma. A National Clinical Guideline. Available at: www.sign.ac.uk and www.brit-thoracic.org.uk. Accessed January 14, 2019.

2. Lavorini $F$. The challenge of delivering therapeutic aerosols to asthma patients. ISRN Allergy 2013;2013:102418.

3. Nikander K, Nicholls C, Denyer J, Pritchard J. The evolution of spacers and valved holding chambers. J Aerosol Med Pulm Drug Deliv 2014;27(1):S4-S23.

4. Terzano C, Mannino F. Aerosol characterization of three corticosteroid metered dose inhalers with Volumatic holding chambers and metered dose inhalers alone at two inspiratory flow rates. J Aerosol Med 1999;12(4):249-254.

5. Newman SP. Spacer devices for metered dose inhalers. Clin Pharmacokinet 2004;43(6):349-360.

6. Raissy HH, Kelly HW, Harkins M, Szefler SJ. Inhaled corticosteroids in lung diseases. Am J Respir Crit Care Med 2013;187(8):798803.

7. Chaplin S, Head S. Clenil Modulite, a CFC-free MDI with no adjustment on switching. Prescriber 2007;18(13):43-46.

8. Leach CL, Davidson PJ, Hasselqulst BE, Boudreau RJ. Lung deposition of gydrofluoroalkane-134a beclomethasone is greater than that of chlorofluorocarbon fluticasone and chlorofluorocarbon beclomethasone: a cross over study in healthy volunteers. Chest 2002; 122(2):510-516.

9. Smyth HDC, Beck VP, Williams D, Hickey AJ. The influence of formulation and spacer device on the in vitro performance of solution chlorofluorocarbon-free propellant driven metered dose inhaler. AAPS Pharm Sci Tech 2004;5(1):32.

10. Barry PW, O'Callaghan C. The optimum length and width for a spacer device. Pharm Pharmacol Comm 2000;6(1):1-5.

11. Tena AF, Clara PC. Deposition of inhaled particles in the lungs. Arch Bronconeumol 2012;48(7):240-246.

12. Wildhaber JH, Janssens HM, Piérart F, Dore ND, Devadason SG, LeSouëf PN. High-percentage lung delivery in children from detergent-treated spacers. Pediatr Pulmonol 2000;29(5):389-393.

13. Pierart F, Wildhaber JH, Vrancken I, Devadson SG, Le Souef PN. Washing plastic spacers on household detergent reduces electrostatic charge and greatly improves delivery. Eur Respir J 1999;13(3): 673678.

14. Araujo FB, Amorim Correa R, Pereira LF, Silveira CD, Mancuso EV, Rezende NV. Spirometry with bronchodilator test effect that the use of large-volume spacers with antistatic treatment has on test response. J Bras Pneumol 2011;37(6):752-758.

15. Said ASA, Harding L, Chrystyn H. Urinary pharmacokinetic methodology to determine the relative lung bioavailability of inhaled beclometasone dipropionate. Br J Clin Pharmacol 2012;74(3):456464.

16. British Pharmacopoeia. Preparations for inhalation. Aerodynamic assessment of fine particles-fine particle dose and particle size distribution. In: British Pharmacopoeia. (Ed, Stationery Office) London; 2005;4:A277-A290.

17. Beeh KM, Beier J, Donohue JF. Clinical trial design in chronic obstructive pulmonary disease: current perspectives and consider- 


\section{Beclometasone Relative Bioavailability With a Spacer}

ations with regard to blinding of tiotropium. Respiratory research 2012;13(1): 1 .

18. Hindle M, Newton DA, Chrystyn H. Investigations of an optimal inhaler technique with the use of urinary salbutamol excretion as a measure of relative bioavailabilty to the lung. Thorax 1993;48(6): 607-610.

19. Menzies D, Nair A, Hopkinson P, McFarlane L, Lipworth J .Differential anti-inflammatory effects of large and small particle size inhaled corticosteroid in asthma. Allergy 2007;65:661-667.

20. Piccinno A, Poli G, Monno R, Goethals F, Nollevaux F, Acerbi D. Extrafine beclomethasone dipropionate and formoterol in single and separate inhalers. Clinic Pharmacol Biopharm 2012;1:102.

21. Rogers SG, Anderson R, Main C, Thompson-Coon J, Hartwell D, Liu Z, et al. Systematic review and economic analysis of the comparative effectiveness of different inhaled corticosteroids and their usage with long-acting beta 2 agonists for the treatment of chronic asthma in adults and children aged 12 years and over. Health Technol Assess 2008;12:19.

22. Battaglia S, Cardillo I, Lavorini F, Spatafora M, Scichilone N. Erratum to: safety consideration of inhaled corticosteroids in the elderly. Drug Aging 2015;32(12):1067-1076.

23. Ruzycki CA, Golshahi L, Vehring R, Finlay WH. Comparison of in vitro deposition of pharmaceutical aerosols in an idealized child throat with in vivo deposition in the upper respiratory tract of children. Pharm Res 2015;3(6):1525-1535.

24. Yazdani A, Normandie M, Yousef M, Saidi MS, Ahmadi G. Transport and deposition of pharmaceutical particles in three commercial spacer-MDI combinations. Comput Biol Med 201;54:145-155.

25. Reznik M, Silver EJ, Cao Y. Evaluation of MDI-spacer utilization and technique in caregivers of urban minority children with persistent asthma. J Asthma 2014;51(2):149-154.

26. Levy ML, Dekhuijzen PNR, Barnes PJ, Broeders M, Corrigan CJ, Chawesb BL, et al. Inhaler technique: facts and fantasies. A view from the Aerosol Drug Management Improvement Team (ADMIT). NPJ Prim Care Respir Med 2016;26:16017.

27. Broeders ME, Sanchis J, Levy ML, Crompton GK, Dekhuijzen PN. The ADMIT series-issues in inhalation therapy. 2. Improving technique and clinical effectiveness. Prim Care Respir J 2009;18(2):76-82.

28. Ehtezazi T, Davies MJ, Seton L, Morgan MN, Ross S, Martin GD, Hutchings IM. Optimizing the primary particle size distributions of pressurized metered dose inhalers by using inkjet spray drying for targeting desired regions of the lungs. Drug Dev Ind Pharm 2015; 41(2):279-91.

29. Lavorini F, Fontana GA, Usmani OS. New inhaler devices: the good, the bad and the ugly. Respiration 2014;88(1):3-15.

30. Mitchell JP, Suggett J, Nagel M. Clinically relevant in vitro testing of orally inhaled products-bridging the gap between the lab and the patient. AAPS PharmSciTech. 2016;17(4):787-804.

31. Wilkes W, Fink, J. Dhand R. Selecting an accessory device with a metered-dose inhaler: variable influence of accessory devices on fine particle dose, throat deposition, and drug delivery with asynchronous actuation from a metered-dose inhaler. J Aerosol Med 2001;14:351360.

32. Sanchis J, Corrigan C, Levy ML, Viejo JL. Inhaler devices-from theory to practice. Respir Med 2013;107(4):495-502.

33. Berger WE, Bensch GW, Weinstein SF, Skoner DP, Prenner BM, Shekar T, et al. Bronchodilation with mometasone furoate/formoterol fumarate administered by metered-dose inhaler with and without a spacer in children with persistent asthma. Pediatr Pulm 2014;49: 441-450.
34. Gachelin E, Vecellio L, Dubus JC. Critical evaluation of inhalation spacer devices available in France. Rev Mal Respir 2014;32(7):672681.

35. Jat KR, Singhal KK, Guglani V. Autohaler vs. metered-dose inhaler with spacer in children with asthma. Pediatr Allerg Immun 2016; 27(2):217-220

36. Hardy JG, Jasuja AK, Frier M, Perkins AC. A small volume spacer for use with breath operated pressurized metered dose inhaler. Int J Pharm 1996;142(1):129-133.

37. Richards J, Hirst P, Pitcarin G, Mahashabde S, Arbramowitz W, Nolting A, Newman SP. Deposition and pharmacokinetics of flunisolide delivered from pressurized inhalers containing non-CFC and CFC propellants. J Aerosol Med 2001;14:197-208.

38. Ditcham W, Murdzoska J, Zhang G, Roller C, Hollen D, Nikander K, Devadson SG. Lung depositiom of 99m Tc-Radiolabelled albuterol delivered through a pressurixzed metered dose inhaler and spacer with face mask or mouthpiece in children with asthma. J Aerosol Med Pulm Drug Deliv 2014;27(1):S63-S75.

39. Nikander K, Nicholls C, Denyer J, Pritchard J. The evolution of spacers and valved holding chambers. J Aerosol Med Pulm Drug Deliv 2014;27(1):S4-S23.

40. Sanders M, Bruin R. A rationale for going back to the future: use of disposable spacers for pressurised metered dose inhalers. Pulm Med 2015;2015:176194.

41. Bisgaard H. A metal aerosol holding chamber devised for young children with asthma. Eur Res J 1995;8(5):856-860.

42. Berg E, Madsen J, Bisgaard H. In vitro performance of three combinations of spacers and pressurized metered dose inhalers for treatment in children. Eur Resp J 1998;12(2):472-476.

43. Dewsbury NJ, Kenyon CJ, Newman SP. The effect of handling techniques on electrostatic charge on spacer devices: a correlation with in vitro particle size analysis. Int J Pharm 1996;137(2):261-264

44. Mitchell JP, Coppolo DP, Nagel MW. Electrostatics and inhaled medications: influence on delivery via pressurized metered-dose inhalers and add-on devices. Respir Care 2007;52(3):283-300.

45. Rau JL. Practical problems with aerosol therapy in COPD. Respir Care 2006;51(2):158-172.

46. Newman SP. Principles of metered dose inhaler design. Respir Care 2005;50(9):1177-1190.

47. Lavorini F, Fontana GA. Targeting drugs to the airways: the role of spacer devices. Expert Opin Drug Deliv 2009;6(1):91-102.

48. Olsson B, Borgstrom L, Lundback H, Svensson M. Validation of a general in vitro approach for prediction of total lung deposition in healthy adults for pharmaceutical inhalation products. J Aerosol Med Pulm Drug Deliv 2013;26(6):355-369.

49. Ruzycki CA, Golshahi L, Vehring R, Finlay WH. Comparison of in vitro deposition pharmaceutical aerosols in an idealized child throat with in vivo deposition in the upper respiratory tract of children. Pharm Res 2014;31(6):1525-1535

50. Mazhar SH, Chrystyn H. Salbutamol relative lung and systemic bioavailability of large and small spacers. J Pharm Pharmacol 2008; 60(12):1609-1613.

51. Nahar K, Gupta N, Gauvin R, Absar S, Patel B, Khademhosseini A, Ahsan F. In vitro, in vivo and ex vivo models for studying particle deposition of inhaled pharmaceuticals. Eur J Pharm Sci 2013;49(5): 805-815.

52. Newman SP, Chan HK. In vitro/in vivo comparisons in pulmonary drug delivery. J Aerosol Med Pulm Drug Deliv 2008;21(1):77-84.

53. Chrystyn H. Is total particle dose more important than particle distribution? Respir Med 1997;91(1):17-19. 